\title{
Article
}

\section{Compassionate wound care: An integrated intervention for people who self-injure}

Rayner, Gillian, Blackburn, Joanna and Ousey, Karen

Available at http://clok.uclan.ac.uk/25487/

Rayner, Gillian ORCID: 0000-0001-7293-525X, Blackburn, Joanna and Ousey, Karen (2018) Compassionate wound care: An integrated intervention for people who self-injure. Nurse Prescribing, 16 (12). pp. 616-620. ISSN 14799189

It is advisable to refer to the publisher's version if you intend to cite from the work. 10.12968/npre.2018.16.12.616

For more information about UCLan's research in this area go to http://www.uclan.ac.uk/researchgroups/ and search for < name of research Group>.

For information about Research generally at UCLan please go to http://www.uclan.ac.uk/research/

All outputs in CLoK are protected by Intellectual Property Rights law, including Copyright law. Copyright, IPR and Moral Rights for the works on this site are retained by the individual authors and/or other copyright owners. Terms and conditions for use of this material are defined in the policies page.

\section{CLoK}

Central Lancashire online Knowledge www.clok.uclan.ac.uk

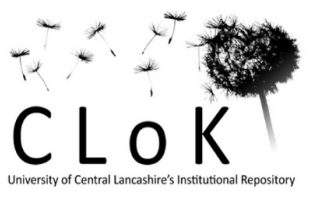


Compassionate wound care: an integrated physical and psycho-social intervention for people who self-injure

\section{$\underline{\text { Introduction }}$}

Self-harm is a significant public health challenge and is at the forefront of the Government's initiative for preventing suicide in England. Indeed, the UK has the highest incidence rates of self-harm in Europe, with over 200,000 hospital attendances per year in England. Many patients who self-harm are treated in the Emergency Department (ED) and Hospital Episode Statistics data demonstrates that patients who self-harm form one of the primary patient groups for ED attendance. Self-harm is commonly considered to be on a continuum that includes suicide at the extreme end and overdosing and more socially acceptable types of self-harm, such as sunbathing and waxing at the other (Babiker \& Arnold 1997). These authors also define Self-injury as physical damage to the skin; cutting burning, picking. This is our specific focus when combining woundcare and compassion and therefore will be the focus of this paper. Geulayov et al., (2015) reported in England that in five hospitals over a 13-year period, self-poisoning accounted for almost $75 \%$ of self-harm. "Selfcutting "(self-injury) was the second highest method of self-harm at $25 \%$. In Northern Ireland, $23.8 \%$ of 8453 presentations of self-harm, were self-injury (specifically cutting) (Northern Ireland Registry of Self-Harm, 2013-2014). Self-cutting is a predominant method of self-harm in the community (Geulayov et al., 2017) and can be particularly susceptible to severe and serious infection, impaired healing due to repeated self-harm and scaring. We consider this is an important area of health provision that can be improved for people who self-injure and enhance their quality of life. 


\section{1) Staff attitudes}

Staff difficulties have been reported in a wide variety of areas of practice especially the emergency department and mental health settings. Most studies have focused on improving nurse's knowledge, awareness and understanding of caring for people who self-harm, although these have mainly focused on the inpatient setting or involved children and young people.

Self-injury (specifically cutting) however, appears to pull a more negative response from staff. It appears that external damage to the self can cause staff to become more emotional and trigger negative thinking and thus it can be more difficult to manage internal experiences, this may interfere with a compassionate and validating helping relationship (Rayner et al, 2005). These authors also write of an interpersonal cycle of self-injury where the staff emotions and beliefs can influence their behaviours (or interactions) with the person who self-injures. If the staff present in a rejecting manner, this can exacerbate the need to self-injure and thus increase presentations at services for help as they continue to attempt to cope with emotions such as shame, guilt, sadness and anger by cutting deeper and more often. This can sometimes lead to an addictive cycle of self-injury. In order to prevent iatrogenic harm from services it is essential that staff do their best to portray a validating compassionate approach to caring without judgement of the person.

Staff in many different settings are instrumental in the care of people who self-injure. They may present in primary care or physical or mental healthcare setting. As selfinjury is such an integration of a physical method of coping with emotional, 
psychological and social issues, it makes sense that we promote a fully integrated approach to care and interventions. If people who self-injure receive compassionate care and support it is anticipated that this will improve their care experience and reduce iatrogenic exacerbation of self-injury.

\section{2) Personal self-harm experience}

Many intervention focused papers focus on the evidence base for the intervention. However, we agree with Ward et al (2012) in that it is essential to co create interventions where possible with people who self-harm. In order to create an integrated approach, the personal experience of many people who self-harm needs to be considered. Historically people who self-harm (and especially self-injure) have experienced rejection by staff providing help and many publications have referred to judgemental staff who consider people who self-harm to be taking resources for people who are "really ill" (Rayner \& Warne, 2015, Rayner et al 2005). We hope this is decreasing but need to acknowledge that previous rejecting responses from staff can affect current perceptions of treatment even if these are more positive. The person who self-harms may expect rejection, rather than acceptance on seeking help. Hulme \& Platt (2007) in their study reported that people who self-harm preferred to receive help in the community and avoid admission to a hospital where possible. This was to reduce their guilt due to taking a bed from "ill patients". They also reported thinking that they were a burden on family and staff. It was recommended by the participants that management of self-harm is a better strategy, rather than prevention or outcome measures of reduction of self-harm. 
Many people who self-harm prefer to privately manage their own wounds, only seeking help when they really have to. Supporting people to manage their self-injury through wound care (internally and externally) can facilitate feelings of self-control, promote self-compassion and enable them to generate additional coping strategies for living (as well as self-harm). In this sense, people who self-harm may benefit from compassionate and validating environments that promote harm minimization approaches. This can start in Primary care then extend through all services and would encourage people to make choices about their self-injury, promoting compassionate self-care to reduce further shame, guilt and self-punishment (Rayner \& Warne, 2015).

\section{3) Wound care Elements}

As self-cutting is the second most common form of self-harm, it is inevitable that a proportion of this group will require wound care management from knowledgeable clinicians in a variety of healthcare settings. Inadequate wound care following cutting can result in impaired wound healing, risk of infection and scarring (Geulayov et al., 2017). If a non-sterile implement has been used to breach the skin it will carry its own invading organisms increasing the risk of infection. Kilroy-Findlay \& Bateman (2016:89) state that from a wound healing perspective, contamination has occurred from both an extrinsic and intrinsic source (implement and skin); multiplication of bacteria will be dependent on the availability of nutrients and the host. As such an accurate wound assessment should be undertaken in line with the Generic Wound Care Assessment Minimum Data Set inclusive of the five key domains General health

Baseline information

Wound assessment 
$>$ Wound symptoms

$>$ Specialist referral.

Supplementary to this should be an exploration and understanding of implements used for the episode to identify potential risk of infection, allowing for timely and appropriate use of antimicrobial wound dressings and if necessary antibiotic therapy. The National Institute for Health and Care Excellence (NICE, 2011) recommend during the assessment clinicians should explore the meaning of self-harm for that person and each episode should be treated in its own right as the persons reasons for self-harm may be different from episode to episode. Referral to mental health services and the tissue viability service may be necessary.

Following publication of the clinical guidelines for the short-term management and prevention of recurrence of self-harm, they promote a holistic approach to treatment, involving both caring for the patient's physical injuries and a psychological assessment to manage the fundamental underlying issues involved in self-harming. The guidelines suggest that the treatment of the injury itself, should take the same course as any other injury and in the case of the management of small, superficial wounds, tissue adhesive is suggested to be an effective and easy treatment option for health care professionals to use to treat this. NICE further highlight the seriousness of some injuries caused through self-harm, e.g. profuse bleeding where management of shock from hypovolaemia and restoration of blood perfusion is a priority, these types of wounds necessitate urgent treatment which should be provided in a timely manner. Not all wounds will be serious and many people with injuries from self-injury attend the Emergency Department (ED) for treatment and care, where the patient's wound will typically be cleansed with saline and a simple dressing applied to help wound healing 
(Hunt, 2017). Many people who self-injure will manage the wounds themselves. Therefore, using products that are easy and simple will improve confidence, reassurance and ownership for the person within their self-care pathway, thus reducing the reliance on the clinician (Hunt 2017). 'Rescue packs' for this group of people have been developed and offered in some areas containing skin and wound cleansing products, gauze to clean and mop up body fluids, an appropriate antiseptic, antimicrobial product (e.g. irrigator, gel, wash or wipe), an appropriate topical secondary dressing that is atraumatic, absorptive for low-to-moderate exudate or blood, adhesive and has a long-wear time (Hunt, 2017).

Ousey and Ousey (2012) described how patients who frequently self-harm need to be provided with information on how to care for their own wounds including how to identify the signs and symptoms of infection, methods of keeping the wound clean (for example, cleaning the wound with warm $0.9 \%$ sodium chloride or water) and the importance of ensuring wound dressings are not removed regularly thus delaying wound healing. Indeed, Babiker and Arnold (1998) identified that developing an understanding of how to look after their own injuries, whilst also recognising when to seek professional treatment and care, could have significant psychological and physical benefits for people who self-harm. Without an understanding of how to treat and manage their injuries, the risk of impaired wound healing, infection and scarring to the person is greatly increased. The Royal College of Psychiatrists (RCP, 2007) provides advice for people choosing to manage their own wounds at home in their Self-harm: Limiting the Damage document and suggests that cutting should only be performed with clean implements to minimise the risk of infection. Small cuts to the 
skin should be managed with a sterile dressing or plaster, whilst bandages are recommended in the case of deeper cuts that bleed significantly.

Appropriate wound care following self-injury is essential to reducing the appearance and severity of scarring. Scarring is a common consequence of cutting and the RCP (2007) highlight several important factors that are essential for good wound management. These include keeping the area clean, ensuring wounds are encouraged to stay closed through appropriate dressing choice, limiting interfering with the healing wound to maximise the chance of wound closure and applying products that are designed to minimise scarring including silicone gel sheets and applying lotions containing vitamins (such as vitamin $A$ and $E$ ) that are known to promote the wound healing process (RCP, 2007). The visible signs of cutting through scarring can be distressing for the individual and an obvious reminder of despair and suffering. The RCP (2007) offers support for people who wish to conceal their scars and advocates the use of a skin camouflage service, which is now provided through the Changing Faces charity, who provide training on the use of specialist cover up creams designed to disguise the appearance of scarring. The support service Life Signs also describe methods of scar reduction and promote regular massage (gently rubbing the area near the scar) to aid healing. Topical treatments such as Bio-Oil, Rescue Oil, Cocoa butter or a Vitamin E body cream can also be applied and are endorsed as treatments for minimising the appearance of scarring. Other techniques include the application of silicone strips or haelan tape, containing Fludroxycortide, which have been known to facilitate wound healing.

\section{4) Psychological Elements}


Self-injury is considered to have a plethora of different functions, but the commonest is considered to be relief of tension or stress (Babiker \& Arnold, 1997) It has also been described as a form of self-punishment an expression of self-criticism (Sutherland et al, 2014) and a method of coping with shame (Rayner \& Warne, 2015). It seems that the role of compassion or lack of compassion is central in all of these functions. Some people who self-injure claim that this prevents them from killing themselves and helps them to cope with life (Babiker \& Arnold, 1997). It could be argued that for these people self-injury is being compassionate to themselves as recognising and attempting to relieve their own suffering. Compassion is also core to the practice of all healthcare practitioners (Beaumont et al'2016). Gilbert (2014) defines compassion as a sensitivity to suffering and distress (in others and oneself) with a desire and motivation to try and do something about this distress. Paul Gilbert developed Compassion Focused Therapy (CFT) to target psychological issues underpinned by shame. This model of therapy draws upon a variety of sciences, including those linked to biology, evolutionary theory, developmental psychology and attachment theory. This model suggests that individuals can learn to develop compassion and balance their 'affect regulating systems'.

Gilbert states that there are three flows of compassion, and that each of these have facilitators, blocks and practices that may lead to their cultivation:

(1) Compassion flows out: people can experience compassion in themselves and then direct it outward toward other people (compassion for others)

(2) Compassion flowing in: people can receive and accept compassion from others (compassion from others) 
(3) Self-to-self compassion: generating and directing compassion to ourselves (self-compassion)

Anecdotal evidence from the first author suggests that often people who self-harm are very compassionate to others. However self-compassion may be missing at times of self-harm (Rayner \& Warne, 2015). There may also be issues when receiving compassion as people may consider themselves unworthy of help and compassion (Ward et al, 2012). Therefore, an intervention focused on receiving compassion from caring professionals and helping the person to enhance their own self-compassion could be useful for people who self-injure or self-harm. This view is further endorsed by Xavier, Gouveia \& Cunha (2016) who state that a psychotherapeutic approach should have a specific focus on the development of a self-compassionate relationship between the self, to counteract feelings of negativity and self-criticism, which perpetuate the desire to initiate self-harm. The CFT model is idea to base self-help material on for people who self-injure.

Many different types of psychotherapy have been used with people who self-harm but there is not one clear leader. In their systematic review, Ward et al (2012) concluded that the relationship with the service provider often accounted for the treatment effects in the 65 papers reviewed. A collaborative and non-cohersive relationship that validates personal experience is required with a focus on improving quality of life rather than a reduction in self harm. The evidence appears to point towards the therapeutic relationship being the most effective component. This relationship can occur in a variety of healthcare roles and doesn't therefore need to be considered a mental health intervention. 
Self-injury is a physical method of coping with emotional and cognitive reactions and is often a private activity, but it becomes interpersonal when people seek help so the social elements of self-harm need to be considered.

\section{5) Social Elements}

Rayner \& Warne (2015) specify a cycle of shame that the person who self-harm may become trapped within. This can maintain the self-harm. In their study people who self-harmed did this after a trigger event where they became ashamed, helpless, sad and angry. The self-harm helped them cope with these emotions but later caused a further external reinforcement of shame when they attended the ED, based on perceived staff reactions.

Wheeler (1996) defines shame as a belief in the unacceptability of personal needs, characteristics and desires in a social relationship. Shame has a focus on a belief that the self is bad or defective, whereas guilt has the focus on the behaviour being bad or defective. Thus, the person and the behaviour are inseparable with shame and this can result in increased emotional impact. A positive aspect of shame is that it is considered to be an appeasement gesture (Gilbert, 2014). Its function is thought to lead to reconciliation after social transgressions and to reduce interpersonal conflict. By feeling ashamed, the person accepts that they may have done something wrong. If self-injury is utilized to cope with shame, this process of reconciliation may be halted in the development of further interpersonal conflict. The expression of shame can bring on a sympathetic response from others, which in turn can motivate an altruistic helping response in others. However, if self-injury is used to cope with 
shame, this helping response can become a rejecting response, as the method of coping is not socially acceptable to others.

Hahn (2004) argues that people internalise devalued and devaluing mental representations (from life experience) when they experience shame. Devalued representations contain a sense of worthlessness and inadequacy, whereas devaluing representations criticize, judge and condemn these experiences. This experience can produce a very critical internal self-dialogue for the person who has self-harmed. It can also effect how they expect to be treated from helpers.

Morrison (1989) states that devalued mental representation ("I'm to blame, I'm worthless, I'm a failure") remains internalised and the devaluing representation is externalised ("You are judging, condemning and blaming me"). Immediately after the self-injury people may expect a negative reaction from others and prefer to hide away and keep the self-injury private. By training people in compassionate wound care, this can help then keep self-injury private, help them to assess risk and to learn how to care for themselves with some compassion, instead of punishing the self again.

So, by educating staff in helping relationships about these interpersonal experiences and encouraging a compassionate validating approach when dressing wounds, it is hoped that this cycle of shame can be avoided or at least minimized. In order to recognise the personal experience of people who self-injure it is essential to bring this into the knowledge of the staff to enhance empathy. Actively involving patients in service design though co-production is central to improving patient-based outcomes, 
satisfaction and quality (Ward et al, 2012). A limited number of the educational resources providing support for people who self-harm have been produced with the participatory involvement of people who self-harm. This is important as co-production is fundamental to producing materials that are designed to guide people who should be in receipt of such supports. Gutridge (2010) considers patient engagement an important aspect when working with people who self-harm.

6) Integrated compassionate wound care package

Interventions that explicitly target a compassionate and validating self-attitude may have a crucial role in limiting the effects and episodes of self-harm. As part of a damage limitation approach, Hunt (2017) introduced 'rescue packs' for patients who repeatedly self-harmed and usually managed their own wounds at home. These packs, containing sterile dressings for patients to manage their physical injuries demonstrated improvements in wound management pre and post injury, reducing primary and secondary care visits. However, these rescue packs were not coproduced with people who self-harm. Thus, a harm reduction/harm minimisation approach can limit the extent of serious injury or infection, but co-producing a holistic educational and self-management package, adding the element of compassionate self-care to address the emotional and cognitive triggers and maintenance factors for repetitive self-harm, offers a unique element to improving patient outcomes and experiences. In order to improve engagement in positive care experiences in physical and mental health settings, this intervention is designed to increase knowledge around how to compassionately self-manage the physical and emotional consequences of self-injury, thus reducing connection in a possible addictive and punishing cycle of self-harm. By providing people with the necessary compassion, 
knowledge and self-awareness to manage their own wounds at home, visits to all primary and secondary care may be reduced.

\section{$\underline{\text { Conclusion }}$}

By providing supportive and validating demonstration of physical and mental health care after self-injury, people would be able to manage the consequences of this in a compassionate caring manner, and thus exit exacerbation of shame. The role of the nurse is pivotal as they would often be seeing the patient for longer-term wound or psychological care and are thus in an excellent position to model compassionate and validating care. Some people will already be very experienced at this but may have had previous rejecting and negative experiences from staff. Some may also feel they do not deserve to be helped and therefore become dependent on others to care for them. Rather than continuously reinforcing a dependant relationship, nurses can be central to a caring health educational approach, promoting compassionate wound care and helping the patient move towards compassionate self-care and self-worth. This will hopefully reduce the cycles of shame, which in turn could avoid exacerbation of self-injury. The self-care component will also hopefully reduce the need for people who self-jure to attend health provision in order to get their wounds dressed unless these become infected or they have increased risk of suicide. 


\section{$\underline{\text { References }}$}

Babiker, G \& Arnold, L (1997) The Language of Injury: comprehending selfmutilation. John Whiley \& Sons

Beaumont, E., Irons, C., Rayner, G. \& Diagnall, N. (2016) Does compassion-focused therapy training for health care educators and providers increase self-compassion and reduce self-persecution and self-criticism?. The Journal of Continuing Education in the Health Professions ;36(1):4-10

Geulayov G, Kapur N, Turnbull P, Clements C, Waters K, Ness J, Townsend E \& Hawton K (2016): Epidemiology and trends in non-fatal self-harm in three centres in England, 2000-2012: findings from the Multicentre Study of Self-harm in England. BMJ open 6, e010538.

Gilbert, P. (2014) The origins and nature of compassion focused therapy. British Journal of Clinical Psychology, 53(1): 6-41.doi:10.1111/bjc.12043

Gutridge, K. (2010). Safer self-injury or assisted self-harm? Theor Med Bioeth, 31, 1, 79-92.

Hahn, W. (2004). "The role of shame in negative therapeutic reactions." Psychotherapy:Theory, Research, Practice, Training 41(1): 3-12.

Hume, M \& Platt, S (2007) Appropriate interventions for the prevention and management of self-harm; a qualitative exploration of service-users views. BMC Public Health 7:9.

Hunt S (2017) Management of self-harm wounds Made Easy. London: Wounds UK. Available from: www.wounds-uk.com

Kilroy - Findlay A, Bateman S (2016) Case studies: Octenilin Wound Irrigation Solution and Octenisan Wash in self-harm wounds Wounds UK 12:4: 88-94

National Institute for Health and Clinical Excellence (2011) Self-Harm in over 8s: Longer term management. Available at: https://www.nice.org.uk/guidance/ cg133 (accessed 26/07/18)

Morrison, A. (1989). Shame: The Underside of Narcissm_Hillsdale, Laurence Earlbaum.

Ousey C \& Ousey, K. (2012). Management of self-harm wounds. Nursing Standard, $27,9,58-66$.

Rayner GC, Allen SL \& Johnson M (2005): Countertransference and self-injury: a cognitive behavioural cycle. Journal Of Advanced Nursing 50, 12-19. 
Rayner, G \& Warne, T. (2015). Interpersonal processes and self-injury: a qualitative study using Bricolage. Journal of Psychiatric and Mental Health Nursing, 23, 1, 5465.

Royal College of Psychiatrists (2007). Self-harm: Limiting the Damage. Available at: https://www.rcpsych.ac.uk/pdf/Self-harm\%20\%20\%20Limiting\%20the\%20Damage\%20Final.pdf. [Accessed 31/07/2018.

Sutherland O., Dawczyk A., De Leon K., et al.(2014) Self-compassion in online accounts of nonsuicidal self-injury: an interpretive phenomenological analysis. Counselling Psychology Quarterly 27, 409-433.

Ward,J., DeDotte,C.,Bailey, D.,(2012) Service user involvement in the evaluation of psychosocial interventions for self harm: a systematic literature review. Journal of Research in Nursing, 18(2) 114-130.

Wheeler G. (1996) Self and Shame. A New Paradigm for Psychotherapy. JosseyBass, San Fransico.

Xavier, A., Pinto Gouveia, J., \& Cunha, M. (2016). Non-suicidal self-injury in adolescence: The role of shame, self-criticism and fear of self-compassion. Child \& Youth Care Forum, 45(4), 571-586. 